\section{Mídia e violência: um olhar sobre o Brasil}

\author{
Denise W. Carvalho, ${ }^{1}$ \\ Maria Teresa Freire ${ }^{1}$ \\ e Guilherme Vilar $^{2}$
}

Como citar: Carvalho DW, Freire MT, Vilar G. Mídia e violência: um olhar sobre o Brasil. Rev Panam Salud Publica. 2012:31(5):435-8.
Os países latino-americanos seguem na direção de inibir o aumento da violência, em todas as suas formas. Entretanto, o Brasil ocupa a sexta posição no ranking mundial da Organização Mundial da Saúde (OMS) $(1,2)$, o que sugere que os esforços do governo brasileiro não têm sido suficientes para trazer segurança à sociedade, sendo os jovens as principais vítimas.

A violência faz parte da história da humanidade desde a sua origem. A literatura sobre esse assunto é prolífera, tendo recebido a contribuição de muitos pensadores ao longo do tempo. Para Marx, a violência advinha das relações expressas pelo capital, pela luta de classes e pela exploração da mão de obra assalariada. Hegel entendia a violência como inerente ao ser humano, enquanto Nietzsche se concentrava no combate à injustiça, defendendo que a violência mantinha uma função de memória sobre os efeitos de ações proibidas pela sociedade (3). Autores como Bauman (4), Giddens (5), Chauí (6), Porto (7), Carvalho (8) e Fausto Neto (9) compartilham a preocupação com os avanços da violência, discutindo aspectos gerais e sociais de seus efeitos.

Na definição de Michaud (10):

\begin{abstract}
Há violência quando, numa situação de interação, vários atores agem de maneira direta ou indireta, maciça ou esparsa, causando danos a uma ou mais pessoas em graus variáveis, seja em sua integridade física, seja em sua integridade moral, em suas posses, ou em suas participações simbólicas e culturais. (p. 11)
\end{abstract}

SINOPSE

O presente artigo discute a espetacularização e a utilização da violência pela mídia para captar audiência, citando casos brasileiros, assim como os possíveis papéis da mídia no incentivo ou redução da violência. O tema violência perpassa a configuração das sociedades e seus diversos elementos, dentre os quais a mídia se destaca. O debate considera que os meios de comunicação, como produtores de sentido, podem contribuir para a transformação de comportamentos e hábitos sociais a partir de uma abordagem que valorize a igualdade, a cidadania, a liberdade e a segurança dos sujeitos. Ao restringir a importância e a ênfase ao assunto violência, o discurso midiático pode contribuir para uma cultura mais equânime no sentido de promover a redução dos indices de violência.

Palavras-chave: violência; comunicação em saúde; informação; meios de comunicação de massa; Brasil.

1 Pontifícia Universidade Católica do Paraná (PUCPR), Escola de Comunicação e Artes, Curitiba (PR), Brasil. Correspondência: Denise W. Carvalho, denisewerneck.f@gmail.com

2 Universidade Federal Rural de Pernambuco (UFRPE), Departamento de Estatística e Informática, Recife (PE), Brasil.
O conceito abarca os planos antropológico e sociológico: antropológico porque os instintos são entendidos como derivados da cultura, o que torna o desconhecido hostil, originando a agressão, a ira e o combate; e sociológico por admitir diferença de interpretações, destacando que um sistema é constituído de variáveis associadas ao meio ambiente, equilibrando o comportamento em sociedade.

Ao abordar a violência a partir das diferentes dimensões da vida social, o conceito de Michaud (10) permite diferenciar as dimensões material e simbólica ao considerar que, como fenômeno, a violência varia de uma sociedade para outra. Contudo, a OMS alerta para a necessidade de um consenso mundial sobre o que se considera como violência, que permita comparar os dados entre os países para construir uma base sólida de conhecimento (11).

Nesse contexto de violência e cultura, é preciso considerar os avanços das tecnologias da comunicação e da informação, que projetaram a informação a patamares jamais observados. Das mídias impressas às eletrônicas, das redes sociais aos blogs e microblogs, a sociedade nunca produziu nem recebeu tanta infor- 
mação como nos dias atuais. O celular, por exemplo, no decorrer de seus cerca de 40 anos, integrou-se completamente ao cotidiano das pessoas. Esse grande acesso à tecnologia e à informação serviu, de um lado, para trazer facilidade e conforto à vida das pessoas; de outro, trouxe também o distanciamento ao qual se refere Caldeira (12) quando alerta para a distância entre as classes nas cidades contemporâneas como um dos fatores decorrentes do crescimento irreversível da tecnologia. Conforme Caldeira, essa transformação do espaço público em privado é uma das heranças que indiretamente conduzem à violência (12). A informação produzida ficou muito mais rápida, plural e acessível, mas também confundiu os critérios de prioridade, seleção e de estabelecimento de espaços.

A transformação da informação em produto exige que ela assuma as características associadas a qualquer processo industrial: a necessidade de uma relação econômica entre o que é produzido e aqueles que consomem essa produção. Assim, a informação se desvincula de sua principal função, que é garantir à coletividade condições de cidadania, visando a instruir, noticiar, indagar, esclarecer e dar forma aos questionamentos da população (13).

É o que se observa na intensidade da divulgação do caso de um grupo de meninas de 7 a 13 anos apreendidas diversas vezes fazendo arrastão nas ruas de São Paulo. Na delegacia, em depoimento, uma das mães se dirigiu à filha da seguinte forma: "- Volta ao mesmo local do crime. Mas é besta mesmo". A entrevista foi exibida em rede nacional e pela Internet (8).

Uma articulação entre recursos e políticas da administração pública tem sido valorizada por vários autores, como Caldeira (12), Leon (14), Minayo (15), Fausto Neto (9), Maricato (16), Misse (17) e Chauí (6), para conter a violência nas cidades.

\section{AS RESPONSABILIDADES DA MÍDIA NO ENFRENTAMENTO DA VIOLÊNCIA}

Para fugir das medidas coercitivas ou inibitórias, o crime organizado ocupa cidades menos preparadas para lidar com a violência. É o que acometeu a Cidade de Curitiba, no Sul do Brasil, nos últimos anos. Nessa cidade, crimes de grande impacto foram vividos pela comunidade e exibidos exaustivamente pela televisão. Um exemplo forte foi o caso de uma menina de 9 anos encontrada dentro de uma mala na estação rodoferroviária de Curitiba, na madrugada de 4 de novembro de 2008 (13). A violência que vitimou Rachel Maria Lobo Genofre ocupou incessantemente a mídia televisiva e internacional, por várias semanas.

Ao divulgar crimes, os veículos se preocupam com pormenores das situações, tornando a violência um grande e minucioso assunto. A informação jornalística já não basta; o importante passa a ser a perpetuação do interesse pelo crime, comparável ao que ocorre nas novelas, no sentido de levar ao extremo os acontecimentos para envolver os indivíduos. Nesse particular, destaca-se o caso da menina brasileira Isabela Nardoni (6), defenestrada do sexto andar de um edifício resi- dencial de São Paulo na noite de 29 de março de 2008. O caso foi exaustivamente explorado pela imprensa, o que gerou uma espécie de notícia seriada. Mesmo na ausência de algum fato novo, o caso era exposto durante grande parte do dia, com imagens e interpretações excessivamente repetidas e exploradas, levando à conclusão de que, para ganhar a audiência, tudo se justificava: a transformação de heróis em anti-heróis e de vítimas em agressores e novamente em vítimas.

Agressores e criminosos são tratados como celebridades nas capas das revistas, como é o caso do traficante Luiz Fernando da Costa, de codinome Fernandinho Beira Mar (16), várias vezes entrevistado em revistas eletrônicas e estampado nas capas de importantes revistas no Brasil por seus feitos "magníficos". Nesse tipo de discurso, os criminosos são apresentados como pessoas de hábitos comuns ou de hábitos exóticos, conforme o que render mais audiência. Entrevistas são conduzidas na sala de visitas dos agressores, a exemplo do mesmo casal Nardoni, acusado de haver defenestrado a menina Isabela. Os acusados concederam entrevista a uma única rede de televisão, sob a condição de que as perguntas fossem formuladas previamente. Em outro caso, uma apresentadora de TV conduziu, ao vivo, por telefone, uma entrevista com o sequestrador de uma adolescente de 15 anos, Eloá Cristina Pimentel, no momento em que a polícia tentava negociar com o criminoso. Em suas falas, a apresentadora manifestava orgulho por entrevistar o sequestrador, ignorando que o feito atrapalhava o trabalho da polícia. A adolescente veio a falecer em 18 de outubro de 2008, vítima de morte cerebral causada por tiro na cabeça que partiu do agressor, Lindemberg Fernandes Alves, a quem a apresentadora considerava que "não é bandido, é um trabalhador". A entrevista ocupou blocos inteiros da programação.

Especialistas são convidados a analisar os casos em ambientes que simulam uma conversa entre amigos, como uma tarde de domingo ou uma conversa depois do trabalho. Em um clima informal, a violência é apresentada como um elemento comum ou banal, e entre o horror, o escândalo, a raiva e o medo, o telespectador não consegue se livrar do assunto, que já agenda a conversa no ônibus, no condomínio, no clube ou no trabalho.

A cultura da violência é promovida pela mídia como uma resposta ao cotidiano social que busca combater a rotina, proteger-se e livrar-se do perigo, em uma negação que equivaleria a uma pessoa dizer "ainda bem que não aconteceu comigo". Não importa mais a informação, mas o quanto o elemento violência é capaz de ser mantido a fim de expiar a angústia dos indivíduos.

No outro extremo, para a mídia, a violência também é capaz de criar ou manter significados. As imperfeições dos indivíduos, conhecidas como contrárias à virtude - luxo, lascívia, avareza, orgulho - , são reforçadas pelo destaque ao sofrimento das vítimas. A realidade e o sofrimento do outro, comparados à indignação, à compaixão, aos sentimentos de perda e à angústia, reforçam as virtudes do cidadão comum, 
que pode julgar-se a si mesmo como justo, solidário ou generoso, conforme a situação lhe permitir.

O cenário da violência é promovido também na forma como os contrastes sociais são apresentados, quer seja nos filmes, nas novelas, nas propagandas ou no telejornalismo. Pela necessidade de promover o consumo, valorizam-se elementos não oferecidos à maioria da população: padrões de vida elevados, beleza e facilidade na obtenção de objetos ou determinadas condições sociais. A mídia, então, relega a informação a um nível secundário na busca pela audiência e pela identificação dos telespectadores com hábitos e atitudes planejados ou reconhecidos quando da pesquisa e do planejamento da programação.

Assim, algumas das funções da mídia são corrompidas, por exemplo, a prevenção e a educação dos públicos para combater e proteger-se da violência e da criminalidade. Ao abordar exaustivamente situações de risco, de perigo ou de violência experimentada, a realidade se mistura à fantasia, e os sentidos humanos são influenciados pelo imaginário, reduzindo ou ampliando as ameaças dos ambientes.

Quando o comportamento de determinado personagem de novela é repetido nas ruas por pessoas comuns, a ficção vira realidade e as situações experimentadas podem se entrelaçar, como em uma rede. Dessa forma, ao intercalar realidade e modelos, a mídia pode auxiliar as políticas públicas que priorizam a segurança de cidades e regiões, demonstrando ações necessárias para coibir, suprimir ou diminuir as causas da violência. Ações conscientes da mídia na produção de matérias, reportagens, novelas, filmes, documentários ou mesmo na programação infantil podem servir à promoção dos direitos humanos fundamentais: 0 direito à vida, à liberdade e à cidadania.

A responsabilidade dos meios de comunicação também abrange o desafio de apresentar soluções para o enfrentamento da violência. Raramente as matérias de jornais, revistas, TV e Internet apontam uma solução para a criminalidade. Os programas de variedade trazem assuntos de rotina da sociedade, promoção ou vendas de produtos, e as revistas se colocam em posição bem definida sobre o assunto, supostamente tentando entendê-lo e analisá-lo. Já na Internet, páginas são atualizadas minuto a minuto, e a arquitetura das informações conduz o internauta por caminhos, link a link. Um exemplo, nesse caso, está na morte da juíza Patricia Acioli, assassinada com 21 tiros quando chegava a casa no dia 11 de agosto de 2011 (17). O caso, amplamente noticiado pela mídia, foi relatado com atualização quase instantânea de informações, inclusive sobre o velório e o enterro. A maior rede de televisão do país utilizou os seguintes títulos para as matérias sobre o assunto: "Ela nunca se acovardou, diz a irmã"; "Momento de silêncio"; "Marcada para morrer" (18).

Outro fator que se refere ao modo como os meios de comunicação exploram os temas relacionados à violência diz respeito a um antigo comportamento do ser humano, o gosto pela tragédia e o interesse quase macabro que os indivíduos mantêm uns sobre os ou- tros. Fato ou ficção, a espécie humana sempre se deixou atrair por tragédias. De certa forma, não se pode atribuir à mídia o incentivo, a influência e o aumento da violência, e o fato de a mídia explorar temáticas associadas à violência não pode ser entendido diretamente como causa imediata do crescimento da violência ou de comportamentos violentos. Desse ponto de vista, associar diretamente a programação da mídia ao comportamento violento de grupos ou pessoas significa desviar o foco do problema, deixando de olhar as raízes mais profundas das verdadeiras causas, que incluiriam interações sociais, questões culturais, distribuição de renda, desenvolvimento e educação, por exemplo. Assim, o fato de os indivíduos se identificarem com os conteúdos não significa que reproduzirão atitudes e comportamentos violentos, mas, antes, que tais conteúdos poderão ser entendidos ou percebidos como metáforas, as quais servirão simplesmente para direcionar suas ansiedades e pressões sociais.

No outro extremo, Porto (18) faz um alerta para os perigos dos meios de comunicação:

\begin{abstract}
Os meios de massa, se não são diretamente responsáveis pelo aumento da violência e da criminalidade, seriam, quando menos, um canal de estruturação de sociabilidades violentas, já que aí a violência é, não raro, apresentada como um comportamento valorizado. (p. 160)
\end{abstract}

Jornais, revistas, rádios, TV e Internet figuram entre as grandes mídias que ditam tendências e exercem fascínio nos públicos. Por meio de abordagens, discursos e imagens, ou influenciando a opinião pública, inserem-se nos organismos da sociedade e se mostram capazes de reafirmar valores como a liberdade, a paz e a solidariedade.

Por certo, não se pode considerar ser da mídia a única responsabilidade sobre o estímulo ou o incentivo a variadas formas de violência, ou sobre a promoção de comportamentos violentos. Porém, não se pode negar que os impactos sociais que ela causa podem originar a banalização do tema, ao explorar atos violentos a partir de imagens e sentidos de conflitos sociais.

\section{CONSIDERAÇÕES FINAIS}

Não se pode atribuir aos meios de comunicação a responsabilidade direta pela promoção da violência como está instituída, mas também cabe a esses meios uma contribuição às políticas de combate à não violência. Entretanto, a mídia explora ao extremo os fatos e acontecimentos violentos, ampliando sua importância e divulgação, às vezes envolvendo-os em uma aura de glória.

À mídia cabe uma parcela das contradições que derivam da relação causa-efeito e que levam aos índices assustadores e por demais preocupantes da violência. Além disso, sua abrangência e cobertura insistente podem influenciar a opinião pública e orientar o processo de decisão de, pelo menos, alguns grupos.

Este texto discute a ideia de que a banalização do tema da violência pelos meios de comunicação acentua 
as diferenças sociais contrárias ao desenvolvimento das especificidades dos sujeitos e reforça o desprezo aos benefícios coletivos, em detrimento dos direitos fundamentais pelos quais se firmaram grande parte das conquistas históricas da humanidade.

Em todo o mundo, a mídia exerce grande força nas dinâmicas sociais e culturais, de forma que os esforços para a contenção da violência passam pelo modo como os meios de comunicação pautam o tema. Seja em entrevistas, artigos, comentários, discussões ou aparições em programas diversos, a participação da mídia pode ser mais bem aproveitada no combate à violência.

A mídia deve colaborar com a ação policial e não tornar públicas as estratégias policiais de combate aos atos violentos. Deve, também, apoiar as políticas públicas que visam à segurança social, com reportagens, matérias e entrevistas que estimulem o comportamento saudável dos cidadãos.

No combate à violência, a comunicação dos veículos de massa deve ser capaz de tornar a agenda dos meios de comunicação mais responsável, a fim de não espetacularizar as notícias que se relacionem à violência. Deve criar, em seus espaços, mais produtos educativos, destacar as iniciativas de promoção de desenvolvimento e de cidadania, considerando ações governamentais, da iniciativa privada e de organismos sociais. Deve destacar, também, tendências e políticas globais de incentivo à saúde pública como um objetivo de qualidade para a vida de seus receptores, além de selecionar pautas com ética e responsabilidade, apoiando os esforços da OMS no sentido de reduzir as desigualdades e as diferenças sociais.

\section{SYNOPSIS}

\section{Violence and the media: the case of Brazil}

The present paper discusses the sensationalization of violence by the media as a means to increase audience ratings, citing Brazilian cases, as well as the possible roles of the media in promoting or curtailing violence. The theme of violence permeates the patterning of and the various dimensions of society, with emphasis on the media. The debate surrounding this issue assumes that the means of communication, as producers of meaning, can contribute to transform behaviors and social habits based on an approach that values equality, citizenship, freedom, and the safety of individuals. By restricting the importance and emphasis on violence as a topic, the discourse of the media may contribute towards making cultures more egalitarian in their efforts to reduce violence rates.

Key words: violence; health communication; information; mass media; Brazil.

\section{REFERÊNCIAS}

1. World Health Organization. WHO Statistical Information System (WHOSIS). Disponível em: http://www.who.int/ whosis/en/ Acessado em 12 de março de 2012.

2. Waiselfis JJ. Mapa da violência 2011 - os jovens do Brasil. São Paulo: Instituto Sangari/Ministério da Justiça; 2011. Disponível em: http:/ / www.sesp. rr.gov.br/MAPADAVIOLENCIA.pdf Acessado em 19 de março de 2012.

3. Haeyeck CM. Refletindo sobre a violência. Rev Bras Hist Cienc Soc. 2009;1(1). http:/ / www.rbhcs.com/index_arqui vos/Artigo.Refletindo\%20sobre $\% 20$ a\%20viol\%C3\%AAncia.pdf Acessado em 12 de dezembro de 2011.

4. Bauman Z. Modernidade líquida. Rio de Janeiro: Jorge Zahar; 2001.

5. Guiddens A. Sociologia. $8^{a}$ ed. Lisboa: Fundação Calouste Gulbenkian; 2010.

6. Chaui M. Contra a violência. Disponível em: http://www.fpa.org.br/contraviolencia-por-marilena-chaui Acessado em 20 de dezembro de 2011.

7. Porto MSG. Violência e meios de comunicação de massa na sociedade contemporânea. Sociologia. 2002;4(8):152-71.
8. Carvalho S. Garantismo penal e conjuntura político-econômica contemporânea: resistência à globalização neoliberal: breve crítica. Disponível em: http:/ / www.novacriminologia.com.br/ Artigos / ArtigoLer.asp?idArtigo $=2624$ Acessado em 20 de dezembro de 2011.

9. Fausto Neto A. Fragmentos de uma "analítica" da midiatização. Matrizes. 2007;1(2). Disponível em: http://www. revistas.univerciencia.org/index.php/ MATRIZes/article/viewArticle/5236 Acessado em 12 de março de 2012.

10. Michaud Y. A violência. São Paulo: Ática; 1989.

11. Krug EG, Dahlberg LL, Mercy JA, Zwi $A B$, Lozano R, eds. Relatório mundial sobre violência e saúde. Genebra: World Health Organization; 2002. Disponível em: http://www.opas.org.br/cedoc/ hpp/ml03/0329.pdf Acessado em 19 de março de 2012.

12. Caldeira TPR. Cidade de muros. Crime, segregação e cidadania em São Paulo. São Paulo: 34/EDUSP; 2000.

13. Castells M. A sociedade em rede: a era da informação - economia, sociedade e cultura. São Paulo: Paz e Terra; 2008.
14. Briceño-León R. Violence in Venezuela: oil rent and political crisis. Cienc Saude Coletiva. 2006;11(2):315-25. Disponível em: http://dx.doi.org/10.1590/S141381232006000200010 Acessado em 12 de março de 2012.

15. Minayo MCS. Violência contra a mulher adolescente/jovem. Rio de Janeiro: UERJ; 2007.

16. Maricato E. Brasil, Cidades - alternativas para a crise urbana. $2^{\mathrm{a}}$ ed. Petrópolis: Vozes; 2002.

17. Misse M. Crime e violência no Brasil contemporâneo. Rio de Janeiro: Lumen Juris; 2006.

18. Porto MSG. Violência e meios de comunicação de massa na sociedade contemporânea. Sociologias. 2002;4(8):152-71.

Manuscrito recebido em 10 de novembro de 2011. Aceito em versão revisada em 23 de fevereiro de 2012. 